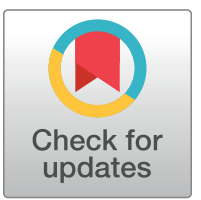

G

OPEN ACCESS

Citation: Walter V, Yin X, Wilkerson MD, Cabanski CR, Zhao N, Du Y, et al. (2018) Correction: Molecular Subtypes in Head and Neck Cancer Exhibit Distinct Patterns of Chromosomal Gain and Loss of Canonical Cancer Genes. PLoS ONE 13(3): e0194674. https://doi.org/10.1371/journal. pone.0194674

Published: March 15, 2018

Copyright: @ 2018 Walter et al. This is an open access article distributed under the terms of the Creative Commons Attribution License, which permits unrestricted use, distribution, and reproduction in any medium, provided the original author and source are credited.
CORRECTION

\section{Correction: Molecular Subtypes in Head and Neck Cancer Exhibit Distinct Patterns of Chromosomal Gain and Loss of Canonical Cancer Genes}

\author{
Vonn Walter, Xiaoying Yin, Matthew D. Wilkerson, Christopher R. Cabanski, Ni Zhao, \\ Ying Du, Mei Kim Ang, Michele C. Hayward, Ashley H. Salazar, Katherine A. Hoadley, \\ Karen Fritchie, Charles J. Sailey, Mark C. Weissler, William W. Shockley, Adam \\ M. Zanation, Trevor Hackman, Leigh B. Thorne, William D. Funkhouser, Kenneth \\ L. Muldrew, Andrew F. Olshan, Scott H. Randell, Fred A. Wright, Carol G. Shores, D. \\ Neil Hayes
}

In S7 Fig, the names of cell lines are incorrectly matched to the underlying data. Please see the corrected S7 Fig here.

\section{Supporting information}

S7 Fig. Copy number plots from the Cancer Cell Line Encyclopedia data. Copy number plots show that genomic events detected in the UNC HNSCC cohort can also be found in the HNSCC cell lines from the Cancer Cell Line Encyclopedia. A. Amplifications in chromosome $3 q$ are seen in all predicted subtypes, and the predicted classical subtype exhibits focal amplification of the region containing SOX2. B. HSC2 (predicted basal) exhibits focal amplification of EGFR, while KYSE510 (predicted atypical) does not. C. Both BIRC31 (predicted mesenchymal) and KYSE180 (predicted classical) exhibit focal deletion of CDKN2A. D. Both SCC15 (predicted mesenchymal) and PECAPJ34 (predicted basal) exhibit focal amplification of CCND1. Note that gains of 11q22 are also seen for SCC15.

(TIF)

\section{Reference}

1. Walter V, Yin X, Wilkerson MD, Cabanski CR, Zhao N, Du Y, et al. (2013) Molecular Subtypes in Head and Neck Cancer Exhibit Distinct Patterns of Chromosomal Gain and Loss of Canonical Cancer Genes. PLoS ONE 8(2): e56823. https://doi.org/10.1371/journal.pone.0056823 PMID: 23451093 